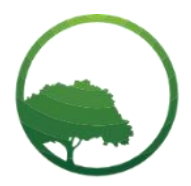

Research in Business \& Social Science

IJRBS VOL 10 NO 8 ISSN: 2147-4478

\title{
The role of perceived severity and vulnerability on COVID-19 in explaining hygiene product purchase behavior towards protection motivation
}

\author{
(D) Desy Gistya Anugerah (a)* (D) Fatchur Rohman ${ }^{(b)}$ (D) Siti Aisjah ${ }^{(c)}$ \\ (a) Management Department, Faculty of Economics and Business, University of Brawijaya, Jl. MT. Haryono No.165, Malang, Indonesia \\ ${ }^{(b, c)}$ Ph.D., Management Department, Faculty of Economics and Business, University of Brawijaya, Jl. MT. Haryono No.165, Malang, Indonesia
}

A R T I C L E I N F O
Article history:
Received 06 December 2021
Received in rev. form 22 Dec. 2021
Accepted 26 December 2021
Keywords:
Protection Motivation Theory,
Purchase Behavior, Behavioral
Intention, COVID-19
JEL Classification:
O15, P36

\begin{abstract}
A B S T R A C T
This study aims to explain the emergence of hygiene product purchasing behavior during the COVID19 pandemic using the Protection Motivation Theory (PMT). Perceived severity and vulnerability as well as protection motivation are variables that are predicted to affect hygiene product purchase behavior during the COVID-19 pandemic. The object of this research is the adult citizens of Malang City who purchase hygiene products during the COVID-19 pandemic. Partial Least Square (PLS) is used in this study to answer the research objectives with the help of SmartPLS 3.3. This study found that perceived severity and protection intention played a role in stimulating the emergence of hygiene product purchase behavior during the COVID-19 pandemic, especially in Malang City.
\end{abstract}

(C) 2021 by the authors. Licensee SSBFNET, Istanbul, Turkey. This article is an open access article distributed under the terms and conditions of the Creative Commons Attribution (CC BY) license (http://creativecommons.org/licenses/by/4.0/).

\section{Introduction}

Corona Virus, also known as Covid-19, was found in late 2019. Coronavirus (COVID-19), a highly infectious illness that poses a danger to human populations globally (Perlman, 2020), is considered the 21st century's third pandemic (Perlman, 2020). The designation of COVID-19 as a worldwide pandemic has spurred governments in various nations to implement measures aimed at preventing the spread of the virus, which has affected how the international community behaves. Changes in people's behavior during the epidemic became an intriguing subject and the focus of researchers in both the social and scientific sectors as they examined the influence of COVID-19 on human existence. According to Treat et al. (2020), people altered their lifestyles during the COVID-19 pandemic.

The changes in behavior during the COVID-19 epidemic also affected the community's economic behavior. Another economic activity that has evolved due to this epidemic is the widespread purchasing of COVID-19 preventative equipment such as masks, hand sanitizers, vitamins, and stamina maintenance medications, both traditional and contemporary. Southeast Asia, for example, is seeing a boom in consumer demand for goods that may help prevent and defend against the transmission of COVID 19, including vitamin supplements, health drinks, hand sanitizer, and masks. Similar behavior has been seen in Indonesia, which has reported a total of 706,830 Covid-19 cases since the virus's discovery on March 2, 2020. (Indonesia.go.id, 2020). Tokopedia was able to record medical equipment sales during the Covid 19 outbreak, with transactions increasing thrice (Beritasatu, 2020). The mask product

\footnotetext{
* Corresponding author. ORCID ID: 0000-0001-9031-3075

(C) 2021 by the authors. Hosting by SSBFNET. Peer review under responsibility of Center for Strategic Studies in Business and Finance.

https://doi.org/10.20525/ijrbs.v10i8.1510
}

Citation: Gistya Anugerah, D., Rohman, F., \& Aisjah, S. (2021). The role of perceived severity and vulnerability on COVID-19 in explaining hygiene product purchase behavior towards protection motivation. International Journal of Research in Business and Social Science (2147- 4478), 10(8), 57-67 
category had a 197-fold rise in sales, while hand sanitizers saw a 72,000-fold increase in sales, not including vitamins (Beritasatu, 2020).

The problem of abnormal behavior toward purchasing COVID-19 preventive equipment became widely explored in 2020. Clemens et al. 2020 performed one of the studies that studied the purchasing behavior of COVID-19 preventative measures, among others. The study focuses on purchases of hygiene goods such as masks, tissues, and hand sanitizers that are out of the ordinary during the COVID-19 pandemic. Laato et al. (2020) did another research on the subject of irrational purchasing behavior for tissues, hand sanitizers, and other cleaning goods. Changes in behavior due to threats or diseases are widely studied using the Protection Motivation Theory. PMT is an extension of the Health Belief Model (HBM). The theory requires that the formation of protection motivation (that is, whether people take protective actions against potential threats) occurs through threat appraisal and comprehensive coping mechanisms (Wang et al., 2019). Thus, PMT is one of the comprehensive theories to explain human behavior closely related to the threat that raises human motivation to protect themselves from these threats.

Several studies, including those by Laato et al. (2020), Camerini et al. (2020), and Ling et al. (2020), employ PMT to explain behavior that arises in response to threats, most notably the COVID-19 pandemic (2019). Research In the United States, Ling et al. (2019) investigate the influence of perceived severity, perceived vulnerability, maladaptive response reward, self-efficacy, and response cost on intention to take seasonal flu vaccine. According to Ling et al. (2019), perceived severity, perceived vulnerability, maladaptive response reward, and self-efficacy all had a substantial influence on the intention of the American public to obtain seasonal flu vaccine, whereas response cost had no effect. According to the findings of Ling et al. (2019), since the American public's perception of the costs associated with seasonal flu is low, response costs do not influence the United States' intention to acquire seasonal flu vaccines.

The large rise of hygiene product buying behavior in Indonesia based on Indonesia's marketplace data is an important phenomenon that deserves an explanation. Malang is one of the cities in East Java Province, which has the highest number of COVID-19 cases in Indonesia. East Java has 399,728 cases of COVID-19 up till the end of 2021. (Covid19.go.id). Due to the significant amount of bulk purchases made in Malang in 2020, hygiene products were lacking (Ramadana, 2020). Ramadan (2020) reported that 24 of Malang City's 26 pharmacies were out of hygiene products, particularly antiseptics and masks. To identify the primary reasons for purchasing behavior for hygiene goods during the pandemic, especially in Malang, research to explain the buying behavior of hygiene products in bulk is required. As a detailed model for explaining behavioral change driven by threats or diseases, PMT is well suited to explaining the development of hygiene product purchasing behavior. As a result, the purpose of this research is to explain how purchase behavior toward hygiene items (masks, antiseptics, and disinfectants) might develop as a result of COVID-19 protection. Therefore, this study aims to explain how buying behavior towards hygiene products (masks, antiseptics, and disinfectants) can arise due to protecting against COVID-19.

\section{Literature Review}

\section{Theoretical Background and Hypotheses Development}

\section{Customer Behavior}

Over the last few decades, behavior has become an exciting topic of discussion, especially in the economic field. Behavioral economics is a field of study concerned with enhancing the explanatory and predictive potential of psychological and logical approaches to economic theory (Camerer and Loewenstein, 2004). Humans as rational homo economicus are insufficient for explaining, forecasting, and controlling economic action. Gary Becker, Herbert Simon, George Akerlof, and Daniel Kahneman were among the scholars who studied behavioral economics in 1979. Kahneman and Tversky (1979) developed a behavioral economic theory that attempts to comprehend people in the same way as a psychologist, such as rational beings, emotional beings, and social creatures. According to this notion, human judgments are more complicated than simple calculations of profit and loss or advantageous circumstances. The primary subject of debate is how consumers arrange their budgets, money, and other resources while consuming a specific kind or number of products or services.

In the field of management, especially behavioral economic marketing management, it is practically related to consumer behavior (Camerer and Loewenstein, 2004). Consumer behavior refers to the decision-making process and physical activity of persons engaged in evaluating, acquiring, and using products and services. As defined by Kotler and Keller (2012), consumer behavior is the study of how people, groups, and organizations choose, acquire, utilize, and dispose of products, services, ideas, or experiences to meet their needs and desires. Consumer behavior is the study of how people, communities, and organizations choose, purchase, use, and disregard products, services, ideas, and experiences to satisfy consumer needs and desires. Meanwhile, the American Marketing Association defines consumer behavior as a dynamic interaction between affective, cognitive, behavioral, and environmental aspects by which humans carry out exchanges in their lives.

\section{Protection Motivation Theory}

Protection Motivation Theory (PMT) (Maddux and Rogers, 1983) is a social theory designed to analyze how individuals react to health threats (eg viruses or sickness) (eg viruses or disease). PMT is frequently employed throughout the history of health research, particularly for health risks (Carfora, 2019), environmental dangers (Bockarjova \& Steg, 2014), and preventive behavior (Prentice- 
Dunn \& Rogers, 1986). (Prentice-Dunn \& Rogers, 1986). The notion of PMT presents a human tendency to participate in protective behavior (ie, immunizing and vaccinating, taking vitamins, etc.) in response to a danger that the individual feels is related to the effect that will be confronted if infected or engaged in the threat. Rogers (2010) created PMT as an expansion of the Health Belief Model (HBM). According to the theory, the establishment of self-protection motivation is required if individuals take protective actions against possible risks that emerge through threat assessment and comprehensive coping mechanisms (Wang et al., 2019). Intention, according to PMT, is the essential determinant of behavior. In the PMT idea, two simultaneous processes, threat assessment and coping appraisal might impact intentions. Individual beliefs about the extent of the negative consequences of a health threat (severity), a person's sensitivity to the negative consequences of a health danger (vulnerability), and the advantages of preventive action all influence threat evaluation. Individual beliefs about the effectiveness of the recommended preventive behavior in preventing the occurrence of negative consequences of the threats faced, beliefs in a person's ability to carry out preventive behavior, and barriers to preventive behavior all influence coping appraisal. According to PMT, when confronted with a threatening event, individuals are most motivated to engage in protective behavior when they believe that a lack of coping action will pose a threat to themselves and that adopting preventive behavior can reduce that threat.

PMT is a theory that elucidates the factors influencing cognitive, social behavior, similar to other behavioral theories such as the Theory of Reasoned Action and the Theory of Planned Behavior (TPB) (Chen, 2016). The strength of PMT is that it considers a person's assessment of the severity and vulnerability of danger and the expenses associated with coping with the threat. As a result, PMT is often used in conjunction with other cognitive theories, such as the Theory of Reasoned Action (TRA) and the Theory of Planned Behavior (TPB) (Chen, 2016). In PMT protection, motivation/intention is the main factor influencing behavior. The critical role of motivation/intention in influencing customer behavior is conveyed in Laato et al.'s (2020) research. Laato et al. (2020), in their research, revealed that a person's desire to make unusual purchases of hygiene products is one of them influenced by the intention to self-isolate to avoid transmission of COVID-19. In his research, Carfora, et al. (2019) also explains that intention will affect the future behavior of individuals. Carfora et al. (2019) conducted a study on how attitudes, subjective norms, perceived behavioral control, trust in the government, farmers, factories, and retailers, and self-identity as a "green consumer" affect the buying behavior of organic milk by first stimulating consumer intentions to buy the product. Research Carfora et al. (2019) concludes how intention has a vital impact on the emergence of purchase behavior in the future. Similar results were also found in Prasetyo et al.'s (2020) research when examining the direct effect of the intention to follow regulations/policies regarding the handling of COVID-19 on actual and adapted behavior. The results of Prasetyo et al.'s (2020) research revealed that a person's intention to comply with recommendations regarding prevention and protection from COVID-19 would make a person willing to carry out actual behavior such as washing hands using hand sanitizers and using masks when leaving the house. The intention to comply with the protocol will also stimulate the emergence of adapted behavior, including regular exercise during the pandemic, maintaining a healthy diet, and always practicing social distancing when outside the home. Based on PMT and previous research on the effect of protection intention on behavior, a hypothesis can be written as

\section{H1: Protection Motivation Affects Hygiene Product Purchase Behavior}

\section{Perceived Severity}

Severity may be described as the degree to which physical harm, psychological harm, social danger, economic harm, or any other kind of danger to others or oneself occurs, as well as threats to other species (Gamma et al., 2020). Wu (2019) expands on this definition by defining perceived severity as an individual's appraisal of the severity or implications of a threat. When a person takes the impact of ignoring a threat seriously, there is a strong likelihood of taking preventive behavior seriously. The rise of preventing behavior is caused by highly beneficial in reducing the severity or avoiding the threat altogether, which reinforces the intention to adopt adaptive behavior against the threat at hand. According to Ling et al. (2019), perceived severity in cases of the disease, particularly infectious diseases, has been extensively discussed in previous studies, including the study of seasonal flu in America by Ling et al. (2019), as well as in cases of COVID-19 discussed in the research of Laato et al. (2020). Ling et al. (2019) explain that perceived severity refers to a person's opinion that the infectious disease is damaging to himself and others around him and humankind in the context of infectious diseases. This belief about the threats of infectious diseases can potentially impact the motivation to protect oneself, which results in protective behavior against certain infectious diseases.

Perceived severity is an essential factor in PMT because it influences protection motivation and preventive behavior. Laato et al. (2020) highlighted in their study that the people of Finland exhibited a penchant for large purchasing of hygiene supplies such as masks and hand sanitizers and the availability of extra food stocks in reaction to the danger of COVID-19. According to Laato et al. (2020), this abnormal purchasing behavior is determined by a person's assessment of the COVID-19 virus's severity. Perceived severity is determined by online information on the COVID-19 virus accessed by someone, resulting in CyberChondria and eventually increasing the need to isolate and protect oneself from COVID-19. The need to protect against COVID-19 eventually contributes to the growth of unusual purchasing behavior. In line with Laato et al. (2020), Chamroonsawasdi et al. (2020) demonstrated that perceived severity and response efficacy directly or indirectly affected the intention to change eating behavior and physical activity. Meanwhile, knowledge of DM and perceived susceptibility indirectly affected a person's intention to change eating behavior and physical activity. Chamroonsawasdi et al. (2020) demonstrate that knowledge affects a person's perception of the danger and vulnerability of developing diabetes mellitus and their ability to manage the disease, which affects their intention to change their eating behavior and physical activity. In contrast to the previous research, Camerini et al. (2019) showed that perceived severity does 
not influence the desire for self-protection. Camerini et al. (2019) used PMT to explain the influence of intrapersonal characteristics, previous experience, and sources of MMR information on the intention to follow official MMR vaccine recommendations in Switzerland, mediated by threat appraisal and coping appraisal, and response cost. Research Camerini et al. (2020) also observed that parents who have had children infected with the smallpox virus and are aware of the MMR vaccine's negative effects are less interested in giving their children the MMR vaccine.

Camerini et al.'s (2019) findings are supported by Ataei et al. (2020) .'s findings that perceived severity did not influence a person's intention or motivation to protect. Ataei et al. (2020) also used the Health Belief Model (HBM), a forerunner to PMT, to explain how perceived severity, vulnerability, and self-efficacy might encourage farmers to use green pesticides to minimize environmental harm. Ataei et al. (2020) observed that since they were unaware of the consequences of using non-natural pesticides on the environment, they were less motivated to safeguard their agricultural land using green pesticides.

Thus, based on many past studies about the importance of perceived severity in motivating people to engage in self-protection, the hypothesis might be stated as follows:

\section{H2: Perceived Severity Affects Protection Motivation}

H3: Perceived Severity Affects Hygiene Product Purchase Behavior

\section{Perceived Vulnerability}

Vulnerability is the conditional likelihood that a dangerous event will occur in the absence of adaptive activity or a modification of current behavior in response to the threat encountered (Gamma et al., 2020). When people sense danger, they modify their behavior to assess the risk they encounter and their ability to accept or reject the threat (Workman et al., 2008). Wu (2019) explains a person perceives a danger not just about the severity experienced if the threat is received but also the probability of being assaulted by the threat. Perceived vulnerability refers to an individual's appraisal of their chances of receiving danger. Wu (2019) also notes that one's susceptibility may influence one's judgment of a danger to the threat rather than the threat's severity. The perceived vulnerability may be determined in the setting of an infectious illness or pandemic, as shown in the study of Bashirian et al. (2020) and Ling et al. (2019). Perceived vulnerability can be determined by a person's evaluation of his susceptibility to contracting the disease. This idea motivates an individual to engage in adaptive behavior to protect himself against these infectious illnesses. Ling et al. (2020) investigated the influences of perceived vulnerability, maladaptive response reward, self-efficacy, and response cost on the intention to acquire seasonal flu vaccine in the United States. Research Ling et al. (2020) is inspired by the minimal number of persons willing to get vaccinated against seasonal flu each year in the United States, less than half of the overall population. Less enthusiasm for a vaccine against seasonal is due to the public's lack of trust in the immunization system and worries about the seasonal flu vaccine's potential adverse effects. According to Ling et al. (2019), perceived vulnerability considerably influences the United States' intention to receive a seasonal flu vaccine. Another study that confirms Ling et al.'s (2020) findings is Wang et al.'s (2020). Wang et al. (2020) use PMT to explain the elements that impact farmers' behavior in preventing and managing Non-Point Source (NPS) pollution. Research Wang et al. (2020) demonstrate through PMT that perceived vulnerability may affect a person's intentions and conduct. Wang et al. (2020) discovered that the larger farmers' perceived vulnerability to NPS pollution, the greater their desire to implement management controls, resulting in NPS control implementation in the Middle Route of China's South-to-North Water Diversion Project.

The findings of Ling et al. (2020) and Wang et al. (2020) contradict Yarmohammadi et al. (2014). Yarmohammadi et al. (2014) utilized the PMT model to describe the variables that impact the preventative behavior of female high school students in Isfahan, Iran, during the $\mathrm{A} / \mathrm{H} 1 \mathrm{~N} 1$ pandemic influenza. Yarmohammadi shows in his study that preventative behavior is driven by an intention to protect oneself against influenza $\mathrm{A} / \mathrm{H} 1 \mathrm{~N} 1$. This research demonstrates that perceived vulnerability does not affect female students' motivation in Isfahan, Iraq, to protect themselves against influenza A/H1N1. Instead, motivation is more likely influenced by response efficacy, self-efficacy, reward, and fear. Chu and Liu's (2020) research also revealed that perceptions of the predicted severity and susceptibility to COVID-19 did not affect the intentions of Americans to want to vaccinate; instead, it was fear that influenced the intentions of Americans to want to do the vaccination significantly. Chu and Liu's research (2020) shows that due to the lack of exact information about how the severity and mode of transmission of COVID-19 are unable to stimulate Americans to want to vaccinate, so they only want to vaccinate for fear of news about COVID -19 .

Based on previous research on the relationship between perceived vulnerability and protection motivation and behavior, the following hypothesis can be written:

\section{H4: Perceived Vulnerability Affects Protection Motivation \\ H5: Perceived Vulnerability Affects Hygiene Product Purchase Behavior}

According to several integration models from previous research to explain the buying behavior of COVID-19 protective equipment, the integration model was adopted in this study depicted in Figure 1. 


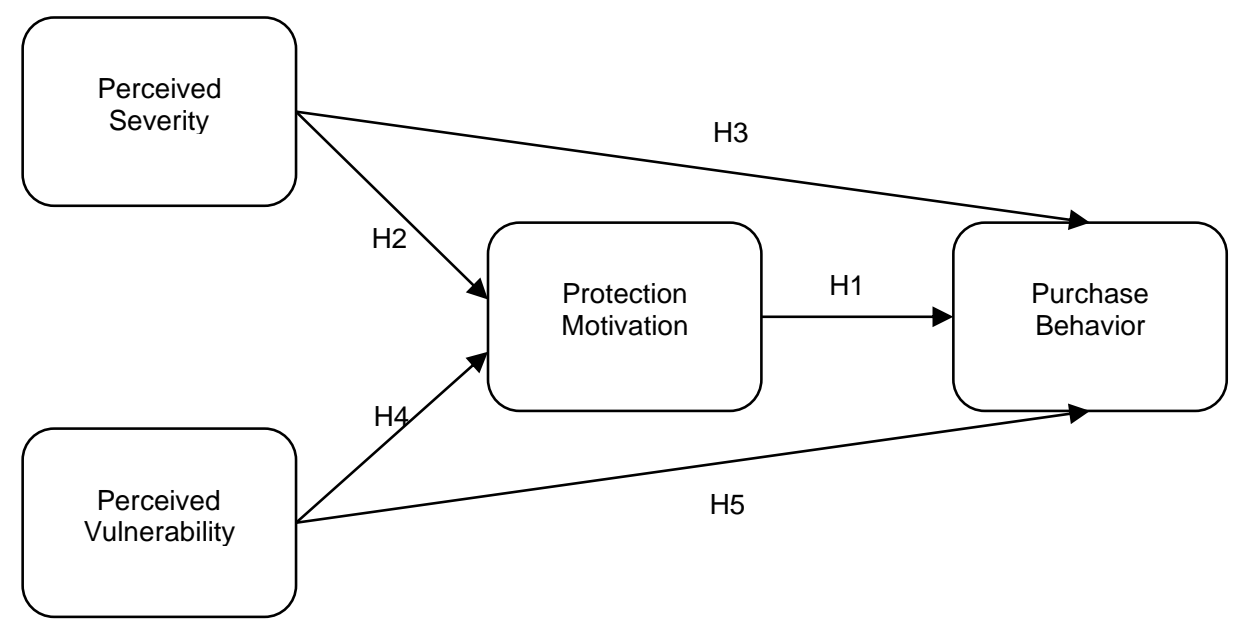

Figure 1: Research Model

\section{Research and Methodology}

\section{Research Instrument}

The measurement of variables in this study was carried out using a questionnaire. Perceived severity was measured using five items suggested by Bashirian et al. (2020) and Cassaro and Pires (2020), which relate to one's opinion of the severity of the COVID-19 virus. Perceived vulnerability in this study was measured by the items used by Diaz (2016) and Nicola et al. (2020) to explain a person's perception of their vulnerability to contracting the COVID-19 virus. Three items related to a person's intention to perform self-protection in the study of Yarmohammadi et al. (2020) were used to measure protection motivation in this study. Finally, purchase behavior is measured using five items in Clemens et al.'s (2020) research. Each item contains an answer using a five scale Likert scale, where one indicates strongly disagree, and five indicates strongly agree.

\section{Population and Sample}

The population used in this study is to know the citizens of Malang City in adulthood. This consideration was taken because of the tendency of more mature decision-making. Hurlock (1959) said that adulthood begins at the age of 18 years. Thus, the population to be studied in this study is Malang City residents aged 18 years and over. The sample collected in this study follows the opinion of Cohen in Hair et al. (2019), which states that the number of samples in using SEM research uses an analytical method that is the maximum number used, the degree of error, and the minimum value of $\mathrm{R}^{2}$ that is an error in the study. The highest number of indicators in the construct of this research is as many as five indicators, namely the perceived severity and purchasing behavior. By using an error degree of 5\%, and the minimum value of $\mathrm{R}^{2}$ according to Cohen in Hair et al. (2019), which is 0.10, the number of samples in this study is 147 samples. The sampling technique used in this research is judgment sampling. Judgment sampling is a specific form of purposive sampling. Assessment sampling requires selecting people who are advantageously positioned or in the best position to provide relevant information. The sample selection in this study was for Malang City residents who were adults and had made independent purchases of Hygiene products, including masks, antiseptics, and disinfectants during the COVID-19 pandemic.

\section{Data Analysis Technique}

The data analysis technique used in this study is Partial Least Square (PLS). PLS explains the influence of factors that can affect hygiene product purchase behavior. PLS is a statistical analysis technique for analyzing structural models, commonly called Structural Equation Modeling (SEM). PLS-SEM explores any possible relationship by explaining the variation in the dependent variables when the model is examined (Hair et al., 2017). Hair et al. (2017) state that the structural model assessment procedure using PLS-SEM included two primary steps: 1) evaluation of the measurement model (outer model); and 2) evaluation of the structural model (inner model). The evaluation of the measurement model was carried out to evaluate whether the questionnaire items were able to measure the variables studied adequately and reliably.

The evaluation of the measurement model in this study consisted of three evaluations: 1) internal consistency (reliability), 2) convergent validity, and 3) discriminant validity (Hair et al., 2017). Convergent validity is the extent to which research instruments in one variable are positively correlated with other instruments in the same construct. Meanwhile, internal consistency reliability proves the instrument's accuracy and consistency. Discriminant validity, by empirical criteria, indicates the degree to which a concept is distinct from other constructs (Hair et al., 2017). Alternatively, Discriminant Validity means that the indicator/dimension/ item of one construct cannot reflect other latent constructs in the model. Discriminant Validity demonstrates how research tools may correctly assess just one latent construct (Mehmetoglu and Venturini, 2021). 
Convergent validity may be determined by examining the value of each measurement item's outer loading. According to some statisticians, if the outer loading is more than 0.70 , the item has strong convergent validity (Hair et al., 2017). However, items with an outer loading of less than 0.4 must be deleted and not included in the subsequent PLS analysis procedure. Hair et al. (2017) stated that items with an outer loading of 0.4-0.7 may also be used if no significant internal consistency changes when an item is eliminated. In the context of internal consistency, PLS-SEM uses composite reliability to measure instrument reliability. Composite reliability is considered more effective in estimating internal consistency than Cronbach's alpha, widely used before the popular structural model. The research instrument is declared reliable if the value is more than 0.7 (Hair et al., 2017). Finally, discriminant validity evaluation was carried out using the Fornell-Larcker Criterion. The Fornell-Larcker Criterion was assessed using the AVE root. Discriminant validity is determined by comparing the value of the square root of the AVE (Average Variance Extracted) variable and its association with other variables in the research. Assume that a latent variable's square root of AVE is higher than its correlation with the constructs of other latent variables. In this instance, a high degree of discriminant validity is attained (Hair et al., 2017).

Evaluating the structural model is carried out to see the relationship between latent constructs by looking at the estimation results of the path parameter coefficients and their level of significance (Hair et al., 2017). The evaluation of the structural model also reviews how much the model can explain the relationship between the exogenous variables and the endogenous variables studied. The evaluation of the internal structural model consists of several parts, including 1) collinearity testing, 2) testing the path coefficient of influence in the structural model, 3) assessment of the coefficient of determination ( $\mathrm{R}^{2}$ ) (Hair et al., 2017).

A collinearity test was conducted to test whether the PLS model found a strong correlation between exogenous variables. A good PLS model should not have exogenous variables experiencing collinearity. One of the methods used in testing the presence or absence of collinearity is to use the Variance Inflation Factor (VIF) and Tolerance (1/VIF). If the value of VIF> 5 or Tolerance $<0.2$, it indicates the existence of collinearity between exogenous variables. Meanwhile, the coefficient of determination $\left(\mathrm{R}^{2}\right)$ is used to assess the role of exogenous variables on endogenous variables in this study. Cohen et al. (2003) suggest the use of Adjusted $R^{2}$ to avoid bias in the number of predictors included in the model. According to Gujarati and Porter (2009), the value of adjusted R squared > $0.25(25 \%)$ indicates that the model is good or the relationship between variables in the study is said to be quite close.

The effect is determined by the significance of the path coefficient of the partial least square (PLS); the path coefficient indicates the amount of an exogenous variable's impact on an endogenous variable. If the path coefficient is statistically significant, the exogenous variable has a statistically significant influence on the endogenous variable (Hair et al., 2017). If the path coefficient's test statistic value (T-statistics) is larger than the test's critical point, the route coefficient is considered significant. The critical point in this research complies with the study's significance level $(\alpha=5 \%)$ is 1.96 . Thus, if the T-statistics value of the test results exceeds 1.96 or the p-value is larger than 5\%, the path coefficient is considered significant (Mehmetoglu \& Venturini, 2021).

\section{Result and Discussion}

The analysis in this study begins with an assessment of the measurement instruments used. The assessment of the measurement instrument was carried out by evaluating the model's output on the PLS. After the measurement instrument in the study was found to be valid, reliable, and consistent, the research hypothesis was tested by testing the relationship between variables in the PLS inner model.

\section{Outer Model Evaluation}

Evaluation of the outer model is carried out before testing the relationship between variables. Evaluation of the outer model is carried out to ensure that the measurement items can measure variables validly and reliably. Internal consistency reliability is the first outer model evaluation conducted in PLS. Table 1 shows the results of testing Internal consistency and Convergent validity in this study.

As shown in Table 1 , the composite reliability value is more than 0.7 , suggesting that the measurement items for each variable in this research are consistent. Additionally, Table 1 includes the convergent validity test results for the outer loading value. According to the convergent validity findings, there are no items with an outer loading of less than 0.4 . Internal consistency was accomplished by retaining measurement items with a loading factor of 0.4-0.7. As a result, all items in this research were determined to be viable and capable of measuring variables consistently. Discriminant validity analysis is next performed to guarantee that the items for each variable are distinct and can only be used to assess the created constructs.

Discriminant validity testing compares the roots of the AVE construct with its correlation with other variables in the model. The square root of the AVE value is shown as a diagonal matrix in Table 1. The AVE root value on perceived severity is 0.598 greater than the correlation of perceived severity with other variables. The square root of AVE in the perceived vulnerability of 0.721 in Table 1 is also greater than its correlation with other variables. Similar perceived severity and vulnerability results were also found in protection motivation and purchase behavior, with the square root of AVE of 0.751 and 0.632 . Thus, based on the evaluation of discriminant validity, it can be stated that the measurement item for each variable is unique and can only be used for the construct being measured. 
Table 1: Evaluation Results of Internal Consistency (Reliability) and Convergent Validity

\begin{tabular}{|c|c|c|}
\hline Measurement Item & $\begin{array}{l}\text { Outer } \\
\text { Loading }\end{array}$ & $\begin{array}{l}\text { Composite } \\
\text { Reliability }\end{array}$ \\
\hline \multicolumn{3}{|l|}{ Purchase Behavior } \\
\hline During pandemics, I always attempt to get masks, antiseptics, and disinfectant & 0.610 & \multirow[t]{5}{*}{0.765} \\
\hline $\begin{array}{l}\text { I always think about how to continue to get masks, antiseptics, and disinfectants during the } \\
\text { pandemic }\end{array}$ & 0.442 & \\
\hline COVID-19 safety gear is critical for me to purchase during the epidemic. & 0.703 & \\
\hline $\begin{array}{l}\text { I believe that purchasing masks, antiseptics, and disinfectants during the pandemic is a } \\
\text { complete waste of money. }\end{array}$ & 0.672 & \\
\hline $\begin{array}{l}\text { During the pandemic, purchasing masks, antiseptics, disinfectants was a complete waste of my } \\
\text { time. }\end{array}$ & 0.696 & \\
\hline \multicolumn{3}{|l|}{ Protection Motivation } \\
\hline I'm willing to wear a mask so I don't get infected with the COVID-19 virus & 0.780 & \multirow[t]{3}{*}{0.795} \\
\hline I am willing to use antiseptic every time I leave the house & 0.783 & \\
\hline I intend to buy vitamins to maintain my immunity during the COVID-19 pandemic & 0.686 & \\
\hline \multicolumn{3}{|l|}{ Perceived Severity } \\
\hline I found that the COVID-19 virus is dangerous & 0.765 & \multirow[t]{5}{*}{0.728} \\
\hline I found that the COVID-19 virus is more dangerous than other viruses & 0.517 & \\
\hline I think handling COVID-19 will cost a lot & 0.698 & \\
\hline I think the COVID-19 pandemic will end in a relatively long time & 0.460 & \\
\hline I think the COVID-19 pandemic in Indonesia is worse than in other countries & 0.488 & \\
\hline \multicolumn{3}{|l|}{ Perceived Vulnerability } \\
\hline I feel vulnerable to the COVID-19 virus & 0.721 & \multirow[t]{5}{*}{0.839} \\
\hline I feel that the environment around me is vulnerable to the COVID-19 virus & 0.573 & \\
\hline $\begin{array}{l}\text { My experience makes me sure if I am easily infected with the disease of friends or people } \\
\text { around me }\end{array}$ & 0.792 & \\
\hline I have a history of being a suspected infectious disease & 0.918 & \\
\hline I feel my family has a chance of being infected with the COVID-19 virus & 0.534 & \\
\hline
\end{tabular}

Table 2: Discriminant Validity Evaluation Result

\begin{tabular}{lllll}
\hline Variable & Perceived Severity & $\begin{array}{l}\text { Perceived } \\
\text { Vulnerability }\end{array}$ & $\begin{array}{l}\text { Protection } \\
\text { Motivation }\end{array}$ & Purchase Behavior \\
\hline Perceived Severity & $\mathbf{0 . 5 9 8}$ & & & \\
Perceived Vulnerability & 0.051 & $\mathbf{0 . 7 2 1}$ & $\mathbf{0 . 7 5 1}$ & $\mathbf{0 . 6 3 2}$ \\
Protection Motivation & 0.388 & -0.328 & 0.511 & \\
Purchase Behavior & 0.504 & -0.207 & & \\
\hline
\end{tabular}

\section{Inner Model Evaluation}

The evaluation of the inner model was carried out to examine the relationship between variables in this study. Testing the relationship in PLS aims to answer the research hypothesis. The first step in testing the inner model is to test the existence of collinearity between exogenous variables. A structural model that does not have collinearity between its exogenous variables. Table 3 shows the VIF value of the exogenous variables in each affected endogenous.

Table 3: Collinearity Test Results

\begin{tabular}{|c|c|c|c|c|}
\hline Variable & Perceived Severity & $\begin{array}{l}\text { Perceived } \\
\text { Vulnerability }\end{array}$ & Protection Motivation & Purchase Behavior \\
\hline Perceived Severity & & & 1.003 & 1.229 \\
\hline Perceived Vulnerability & & & 1.003 & 1.169 \\
\hline Protection Motivation & & & & 1.373 \\
\hline Purchase Behavior & & & & \\
\hline
\end{tabular}

Table 3 shows that perceived severity and vulnerability influence the protection motivation variable. The VIF values of perceived severity and vulnerability with protection motivation as endogenous variables are 1,003, respectively. The VIF value of the exogenous variable on the protection motivation is less than 5, indicating whether or not there is high collinearity between exogenous variables. In purchase behavior, it was also found that the VIF value of exogenous variables, both perceived severity, vulnerability, and protection motivation, was less than 5 , so there was no high collinearity between exogenous variables. Thus, no collinearity was found between exogenous variables in this study so that the structural model can be stated as good and can avoid bias caused by 
collinearity. Without a large degree of collinearity between exogenous variables, it is possible to examine the connection between variables to answer the study hypothesis. Figure 2 illustrates the link between factors and the estimated effect of perceived severity and vulnerability on protection intention and hygiene product purchasing behavior.

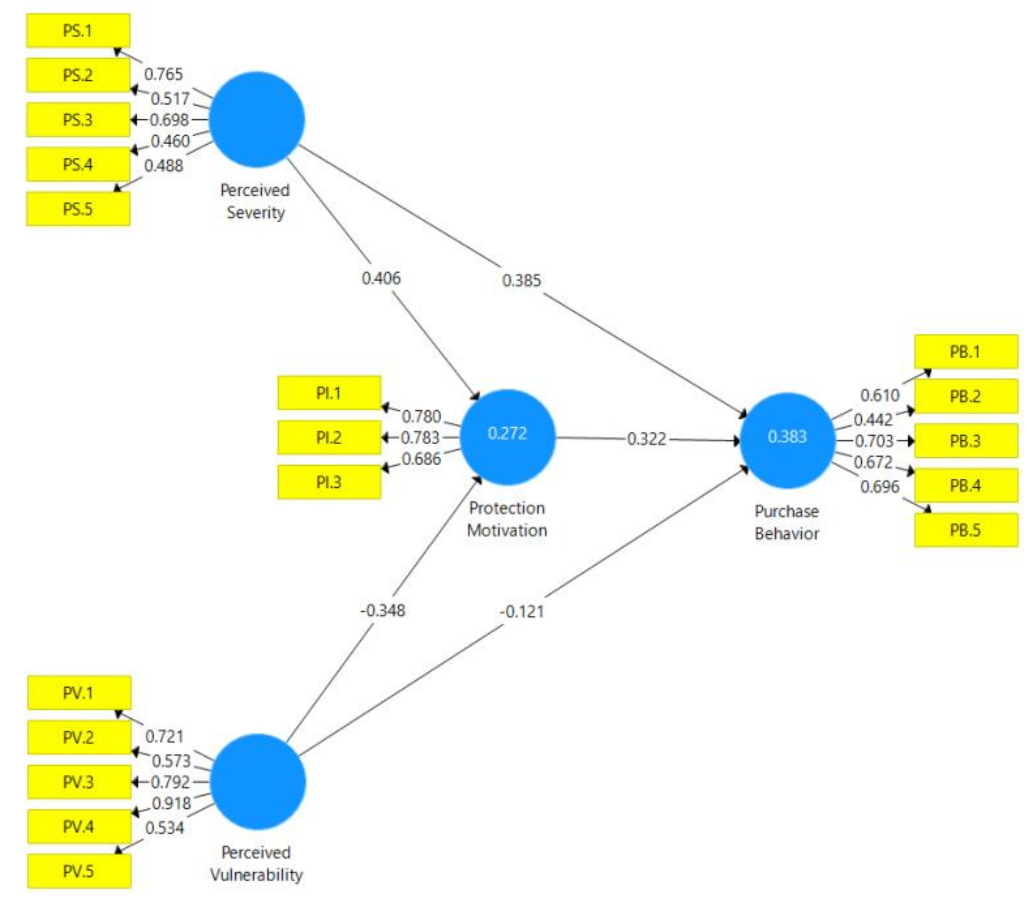

Figure 2: Structural Model of Research Model and Estimated Effect of Exogenous Variable

Figure 2 shows the effect of perceived severity and vulnerability on protection motivation and purchase behavior. The path coefficient for each arrow shows how much influence the exogenous variable has on the endogenous variable. The minus sign on the path coefficient indicates the negative effect of the exogenous variable on the endogenous variable, and vice versa. The path coefficients and test statistic values that will be used for testing the complete hypothesis are presented in Table 4.

Table 4: Hypothesis Testing Result

\begin{tabular}{lllll}
\hline Hypothesis & Relationship & Path Coefficient & T-Statistics & P Values \\
\hline H1 & Protection Motivation $\square$ Purchase Behavior & 0.322 & 2.814 & 0.005 \\
H2 & Perceived Severity $\square$ Protection Motivation & 0.406 & 5.358 & 0.000 \\
H3 & Perceived Severity $\square$ Purchase Behavior & 0.385 & 3.048 & 0.002 \\
H4 & Perceived Vulnerability $\square$ Protection Motivation & -0.348 & 3.228 & 0.001 \\
H5 & Perceived Vulnerability $\square$ Purchase Behavior & -0.121 & 1.125 & 0.261 \\
\hline
\end{tabular}

The test results in Table 4 show that the coefficient of the path of protection motivation on purchase behavior is positive. The TStatistics value of $2.814>1.964$ and $p$-value $=0.005<5 \%$ indicates that protection motivation has been shown to affect hygiene product purchase behavior. The test results support the hypothesis in this study which states that protection motivation affects hygiene product purchase behavior. The results of this study support the research of Laato et al. (2020), Carfora et al. (2019), and Prasetyo et al. (2020). Protection motivation is proven to be the driving force for the emergence of behavior, especially behavior that arises due to threats. COVID-19, a new virus that is considered a global pandemic, can encourage self-protection. The motivation for selfprotection stimulates preventive behavior shown through the purchase of hygiene products such as masks, antiseptics, and disinfectants. The emergence of this protection motivation certainly cannot be separated from people's perceptions of COVID-19.

Perceived severity based on the test results in the table is proven to affect protection motivation. The positive path coefficient of 0.406 with a T-statistic of $5.358>1.964$ and p-value $=0.000<5 \%$ indicates that the greater a person's perception of the severity caused by COVID-19, the stronger their motivation to protect themselves. The results of the PLS test support H2 in this study. This study found results consistent with the research of Laato et al. (2020) and Chamroonsawasdi et al. (2020), which proves that a person's perception of the severity of a threat will motivate them to take self-protection. The important role of perceived severity in motivating self-protection actions turns out to also directly move someone to purchase hygiene products during a pandemic. Table 4 shows that the T-statistics value on the effect of perceived severity on purchase behavior is more than 1.964 , while the p-value of 0.002 is less than 5\%. The value of T-statistics and p-value on the effect of perceived severity on purchase behavior supports the hypothesis of 
this study which shows that perceived severity affects hygiene product purchase behavior. A positive coefficient of 0.385 indicates that the stronger a person's perception of the severity of COVID-19 will stimulate their purchasing behavior towards hygiene products.

The results of this study contradict the results of Camerini et al. (2019) and Ataei et al. (2020). The difference in findings relates to the characteristics of COVID-19 and the impact that is not yet known, especially at the time this research was conducted, namely in 2020. In contrast to the study of Camerini et al. (2019) regarding the MMR vaccination to avoid the impact of the smallpox virus, the concerns of the citizens of Malang City about the impact that COVID-19 can cause are very strong, especially because of the continued news on television and social media about COVID-19 in Indonesia. There is news and uncertainty about the impact that the COVID-19 virus can have, leading to high perceptions of the severity caused so that the motivation for self-protection is getting stronger, which is also reflected in the buying behavior of hygiene products has increased during the pandemic.

Based on Table 4, we find that perceived vulnerability has a net effect on protection motivation. The negative coefficient of -0.348 with T-statistics more than 1.964 and a p-value lower than 5\% proves a significant effect of perceived vulnerability on protection motivation. An interesting finding in this study is that the stronger an individual's perception of their vulnerability to COVID-19 decreases their motivation to protect themselves. Ling et al. (2020) stated that lack of knowledge, especially about self-susceptibility to disease, will impact motivation to protect oneself. Ignorance of self-susceptibility to disease and the absence of routine checks carried out will impact poor self-motivation to carry out self-protection. The negative impact of perceived vulnerability on motivational protection also indicates a form of depression experienced by Malang City residents that no matter how good their immunity is, they will still be infected with COVID-19. Laato et al. (2020) also explained that too much information about COVID19, particularly its adverse effects, will cause Cyberchondria. Cyberchondria itself is closely related to self-confidence to be able to avoid the transmission of COVID-19.

The findings of this study support Yarmohammadi et al. (2014) that perceived vulnerability has no impact on threat prevention behavior. Table 4 shows that the T-statistics on the effect of vulnerability on hygiene product purchase behavior is $1.125>1.964$ and p-value $=0.261>5 \%$, so that it can be stated that H5 in this study is rejected. Chu and Liu (2020) revealed no effect of perceived vulnerability on COVID-19 prevention behavior due to the lack of clear information about COVID-19 and the lack of knowledge about self-susceptibility to infectious diseases.

Finally, the study evaluates the adjusted $\mathrm{R}^{2}$ of the research model. Adjusted $\mathrm{R}^{2}$ in the temporary PLS is one of the criteria trying to be used as a goodness of fit criterion. PLS-SEM is a non-parametric statistical technique that does not have standard goodness of fit criteria like CB-SEM. Therefore, some researchers try to use several criteria that can approach goodness of fit in CB-SEM, one of which is adjusted $R^{2}$. Adjusted $R^{2}$ of more than 0.25 indicates that the model is feasible to use in testing the relationship between variables. Kock (2013) adds the Average Adjusted R-squared (AARS) as one of the overall model goodness of fit criteria. Table 5 shows the $\mathrm{R}^{2}$ and adjusted $\mathrm{R}^{2}$ values for each variable in this study.

Table 5: $\mathrm{R}^{2}$ and $\mathrm{R}^{2}$ Adjusted

\begin{tabular}{llll}
\hline Endogenous Variable & $\mathbf{R}^{\mathbf{2}}$ & $\mathbf{R}^{\mathbf{2}}$ Adjusted & AARS \\
\hline Protection Motivation & 0.272 & 0.261 & 0.316 \\
\cline { 1 - 2 } Behavior & 0.383 & 0.371 & \\
\hline
\end{tabular}

Table 5 shows that the adjusted $\mathrm{R}^{2}$ value for each endogenous variable is greater than 0.250 , indicating that perceived severity and vulnerability can explain protection motivation and purchase happiness. AARS of 0.316 indicates that the model has a goodness of fit to be suitable for use in subsequent studies.

\section{Conclusion}

Hygiene product purchases in Indonesia have become an important phenomenon to explain during the pandemic, even when the COVID-19 pandemic ends. Routine purchases made a significant change in behavior in Indonesia, especially regarding behavior in maintaining health. Regardless of consumers' actual motives in buying hygiene products, this study reveals a high motivation to protect themselves during the COVID-19 pandemic that underlies the buying behavior of hygiene products. Using PMT, the emergence of hygiene product purchasing behavior can be explained well. The concern of the people of Malang City about the severity that COVID-19 can cause is a factor that can motivate them to protect themselves and buy hygiene products during the pandemic.

This study found that protection motivation is an important factor influencing a person's behavior. Protection motivation in this study was proven not only related to maladaptive behavior but also to purchasing behavior. High motivation to protect themselves and those closest to them will move someone to purchase hygiene products. This study also found that lack of knowledge and lack of awareness to do medical check-ups make a person not understand his vulnerability to disease. The results of this study reveal that there are research opportunities in the future by including knowledge as one of the factors that can influence a person's consideration to perform certain behaviors. 
Behavior as something that is also very dependent on the background of each individual makes this research cannot be generalized to explain the buying behavior of hygiene products in other countries in the world. Differences in social and cultural factors from each region will also impact how a behavior can emerge. Research in other areas accustomed to implementing strict hygiene rules will also produce different results. The habit of doing medical check-ups on the people of an area or country will also affect their perception of a certain threat or disease. Therefore, research involving external factors can complement the results of this research in the future. It is also possible to integrate the model with other behavioral theories, such as Theory of Planned Behavior (TPB), Technology Acceptance Model (TAM), etc. The integration of the model in the future is expected to explain customer behavior and behavioral changes that occur, especially those related to threats.

Author Contributions: Conceptualization, DGA, FR, SA.; Methodology, DGA, FR, SA.; Data Collection, DGA, FR, SA.; Formal Analysis, DGA, FR, SA.; Writing - Original Draft Preparation, DGA, FR, SA.; Writing-Review And Editing, DGA, FR, SA. All authors have read and agreed to the published the final version of the manuscript.

Institutional Review Board Statement: Ethical review and approval were waived for this study, due to that the research does not deal with vulnerable groups or sensitive issues.

Data Availability Statement: The data presented in this study are available on request from the corresponding author. The data are not publicly available due to privacy.

Conflicts of Interest: The authors declare no conflict of interest.

\section{References}

Aitken, R., Watkins, L., Williams, J., \&amp; Kean, A. (2020). The positive role of labelling on consumers' perceived behavioural control and intention to purchase Organic Food. Journal of Cleaner Production, 255, 120334. https://doi.org/10.1016/j.jclepro.2020.120334

Ataei, P., Gholamrezai, S., Movahedi, R., \&amp; Aliabadi, V. (2021). An analysis of farmers' intention to use green pesticides: The application of the extended theory of planned behavior and health belief model. Journal of Rural Studies, 81, 374-384. https://doi.org/10.1016/j.jrurstud.2020.11.003

Bashirian, S., Jenabi, E., Khazaei, S., Bashirian, M., Karimi-Shahanjarini, A., Zareian, S., Rezapur-Shahkolai, F., \&amp; Moeini, B. (2020). Factors associated with preventive behaviours of COVID-19 among hospital staff in Iran in 2020: An application of the Protection Motivation Theory. Journal of Hospital Infection, 105(3), 430-433. https://doi.org/10.1016/j.jhin.2020.04.035

Byrne, B. (2016). Structural Equation Modeling With AMOS. Florence: Taylor and Francis.

Camerer, C. F., George, Loewenstein., dan Mathew, Rabin. 2004. Advances in Behavioral Economics. Princeton University Press: Rusel Sage Foundation.

Camerini, A.-L., Diviani, N., Fadda, M., \&amp; Schulz, P. J. (2019). Using protection motivation theory to predict intention to adhere to official MMR vaccination recommendations in Switzerland. SSM - Population Health, 7, 100321. https://doi.org/10.1016/j.ssmph.2018.11.005

Carfora, V., Cavallo, C., Caso, D., Del Giudice, T., De Devitiis, B., Viscecchia, R., Nardone, G., \&amp; Cicia, G. (2019). Explaining consumer purchase behavior for organic milk: Including trust and green self-identity within the theory of planned behavior. Food Quality and Preference, 76, 1-9. https://doi.org/10.1016/j.foodqual.2019.03.006

Chamroonsawasdi, K., Chottanapund, S., Pamungkas, R. A., Tunyasitthisundhorn, P., Sornpaisarn, B., \&amp; Numpaisan, O. (2021). Protection motivation theory to predict intention of healthy eating and sufficient physical activity to prevent diabetes mellitus in Thai population: A path analysis. Diabetes \&amp; Metabolic Syndrome: Clinical Research \&amp; Reviews, 15(1), 121127. https://doi.org/10.1016/j.dsx.2020.12.017

Chen, M.-F. (2016). Extending the protection motivation theory model to predict public safe food choice behavioural intentions in Taiwan. Food Control, 68, 145-152. https://doi.org/10.1016/j.foodcont.2016.03.041

Clemens, K. S., Matkovic, J., Faasse, K., \&amp; Geers, A. L. (2020). Determinants of safety-focused product purchasing in the United States at the beginning of the global covid-19 pandemic. Safety Science, 130, 104894. https://doi.org/10.1016/j.ssci.2020.104894

Gamma, A. E., Slekiene, J., von Medeazza, G., Asplund, F., Cardoso, P., \&amp; Mosler, H.-J. (2017). Contextual and psychosocial factors predicting ebola prevention behaviours using the Ranas approach to behaviour change in Guinea-Bissau. BMC Public Health, 17(1). https://doi.org/10.1186/s12889-017-4360-2

Gujarati, D. N., \& Porter, D. C. (2009). Basic econometrics. Boston, Mass: McGraw-Hill.

Hair, J.F., Hult, G.T.M., Ringle, C.M. and Sarstedt, M. (2017) A Primer on Partial Least Squares Structural Equation Modeling (PLSSEM). 2nd Edition, Sage Publications Inc., Thousand Oaks, CA.

Hair, J. F., Black, W. C., Babin, B. J., \&amp; Anderson, R. E. (2019). Multivariate data analysis. Cengage.

Handayani, I. (2020). Kategori Produk yang Paling Diburu Selama Pandemi Covid-19. Berita Satu. Retrieved 3 July 2021, from https://www.beritasatu.com/digital/618695/kategori-produk-yang-paling-diburu-selama-pandemi-covid19.

Hurlock, E. B. (1959). Developmental psychology. New York: McGraw-Hill.

Indonesia.go.id - Kasus Covid-19 Pertama, Masyarakat Jangan Panik. Indonesia.go.id. (2020). Retrieved 9 April 2021, from https://indonesia.go.id/narasi/indonesia-dalam-angka/ekonomi/kasus-covid-19-pertama-masyarakat-jangan-panik.

Kahneman, D. dan Tversky, A. 1979. Prospect Theory: An Analysis of Decision under Risk. Econometrica, XVLII 1979: $263-291$. 
Kotler, Philip. dan Keller, Kevin. Lane. 2012. Marketing Management Fourteen Edition. New Jersey: Pearson Education Inc.

Laato, S., Islam, A. K. M. N., Farooq, A., \&amp; Dhir, A. (2020). Unusual purchasing behavior during the early stages of the COVID19 pandemic: The stimulus-organism-response approach. Journal of Retailing and Consumer Services, 57, 102224. https://doi.org/10.1016/j.jretconser.2020.102224

Ling, M., Kothe, E. J., \&amp; Mullan, B. A. (2019). Predicting intention to receive a seasonal influenza vaccination using protection motivation theory. Social Science \&amp; Medicine, 233, 87-92. https://doi.org/10.1016/j.socscimed.2019.06.002

Mehmetoglu, M., \&amp; Venturini, S. (2021). Structural equation modelling with partial least squares using stata and r. CRC Press.

Prasetyo, Y. T., Castillo, A. M., Salonga, L. J., Sia, J. A., \&amp; Seneta, J. A. (2020). Factors affecting perceived effectiveness of COVID-19 prevention measures among Filipinos during enhanced community quarantine in Luzon, Philippines: Integrating Protection Motivation Theory and extended theory of planned behavior. International Journal of Infectious Diseases, 99, 312-323. https://doi.org/10.1016/j.ijid.2020.07.074

Wang, Y., Liang, J., Yang, J., Ma, X., Li, X., Wu, J., Yang, G., Ren, G., \&amp; Feng, Y. (2019). Analysis of the environmental behavior of farmers for non-point source pollution control and management: An integration of the theory of planned behavior and the Protection Motivation Theory. Journal of Environmental Management, 237, 15-23. https://doi.org/10.1016/j.jenvman.2019.02.070

Wu, D. (2020). Empirical study of knowledge withholding in cyberspace: Integrating Protection Motivation Theory and theory of reasoned behavior. Computers in Human Behavior, 105, 106229. https://doi.org/10.1016/j.chb.2019.106229

Yarmohammadi, P., Sharifabad, M. A. M., Rahaei, Z., \&amp; Sharifirad, G. (2014). Determination of preventive behaviors for pandemic influenza A/H1N1 based on protection motivation theory among female high school students in Isfahan, Iran. Journal of Education and Health Promotion, 3(1), 7. https://doi.org/10.4103/2277-9531.127556

Publisher's Note: SSBFNET stays neutral with regard to jurisdictional claims in published maps and institutional affiliations.

\section{(c) (1)}

(c) 2021 by the authors. Licensee SSBFNET, Istanbul, Turkey. This article is an open access article distributed under the terms and conditions of the Creative Commons Attribution (CC BY) license (http://creativecommons.org/licenses/by/4.0/).

International Journal of Research in Business and Social Science (2147-4478) by SSBFNET is licensed under a Creative Commons Attribution 4.0 International License. 